\title{
Clostridium algidixylanolyticum sp. nov., a psychrotolerant, xylan-degrading, spore-forming bacterium
}

\author{
D. M. Broda, ${ }^{1,2}$ D. J. Saul, ${ }^{3}$ R. G. Bell ${ }^{2}$ and D. R. Musgrave ${ }^{1}$
}

Author for correspondence: D. M. Broda. Tel: +64 7854 8550. Fax: +64 78548560 . e-mail: d.broda@mirinz.org.nz

1 Department of Biological Sciences, University of Waikato, Hamilton, New Zealand

2 MIRINZ Food Technology \& Research, Hamilton, New Zealand

3 School of Biological Sciences, University of Auckland, Auckland, New Zealand

\begin{abstract}
A psychrotolerant Clostridium species was isolated from vacuum-packed, temperature-abused raw lamb. Colonies of this micro-organism on sheepblood agar were circular with an entire margin, grey-white, translucent and $\beta$ haemolytic. Cells were single, tapered, motile rods. Elliptical subterminal spores were produced in the late stationary growth phase. Spores did not cause swelling of the maternal cells. The micro-organism was obligately anaerobic. In peptone yeast extract glucose starch (PYGS) broth at pH 7.0, the micro-organism grew optimally between 25.5 and $30.0^{\circ} \mathrm{C}$. The temperature range for growth was $2 \cdot 5-32 \cdot 2{ }^{\circ} \mathrm{C}$. At $26^{\circ} \mathrm{C}$, the micro-organism grew optimally at $\mathrm{pH} 6.8$ to 7.0. The $\mathrm{pH}$ range for anaerobic growth was 4.7-9.1. The microorganism was saccharoclastic, hydrolysed starch and degraded xylan. The fermentation products formed in PYGS broth were acetate, formate, lactate, ethanol, butyrate, butanol, hydrogen and carbon dioxide. The $\mathrm{G}+\mathrm{C}$ content of the DNA was $38.4 \mathrm{~mol} \%$. Phylogenetic analyses indicated that the strain belongs to cluster XIVa of the genus Clostridium (sensu Collins et al. 1994). The new strain differed from phylogenetically related clostridia in terms of cellular fatty acid composition, soluble protein profiles and phenotypic properties. On the basis of phenotypic and genotypic characterization data, the strain was assigned to a new species, namely Clostridium algidixylanolyticum. The type strain is strain SPL73 ${ }^{\top}$ ( = DSM 12273').
\end{abstract}

Keywords: Clostridium algidixylanolyticum, psychrotolerance, meat spoilage

\section{INTRODUCTION}

The development of chilled storage and modern packaging technologies (including vacuum packaging), besides extending the shelf-life of meat, created a specific ecological niche for low-temperature-growing bacteria able to proliferate in oxygen-deprived conditions. The majority of the bacteria associated with vacuum-packed cuts of meat are thought to be derived from the exogenous environment of the slaughtered animal (Gill, 1979; Nottingham, 1982) and occur only on the meat surface. Direct carcass contamination occurs during dressing and evisceration (Anonymous, 1993); soil and animal faeces are con-

Abbreviations: FAMEs, fatty acid methyl esters; ML, maximum-likelihood; MP, maximum-parsimony.

The GenBank accession number for the $16 \mathrm{~S}$ rRNA sequence of Clostridium algidixylanolyticum strain SPL73 ${ }^{\top}$ is AF092549. sidered to be the primary reservoirs for this contamination (Bell, 1997).

Clostridia are known to reside and grow in soil, in animal feed and on aerial plant surfaces (Lund, 1986; Ercolani, 1997). In temperate countries, the soil temperature generally favours the growth and survival of psychrotolerant (psychrophilic and psychrophilic), rather than mesophilic, clostridial species (Lund, 1986). Consequently, these low-temperature-growing species from soil or, through ingestion, from faecal sources may contaminate carcasses and thereby become part of the microflora present on vacuum-packed cuts of meat. Little is known, however, about populations of psychrotolerant clostridia with respect to either their primary source in the farm environment or their presence and diversity in vacuum-packed meats. Characteristics of recently described psychrotolerant Clostridium spp. associated with vacuum-packed meats (Collins et al., 1992; Kalchayanand et al., 1993; 
Lawson et al., 1994; Broda et al., 1996) indicate that this group of clostridia may contain metabolically and phylogenetically diverse organisms. During investigations of 'blown-pack' spoilage of vacuum-packed lamb, a psychrotolerant, xylan-degrading Clostridium species was isolated. The aim of this study was to characterize this previously undescribed micro-organism and to determine if it could be differentiated from other psychrotolerant clostridia.

\section{METHODS}

Bacteria and culturing. Stringent anaerobic techniques (Holdeman et al., 1977) were used for media preparation and the culturing of all Clostridium strains. The handling of micro-organisms and the inoculation of test media were conducted inside an anaerobic chamber (Forma Scientific).

Strain $\mathrm{SPL}^{\mathrm{T}}{ }^{\mathrm{T}}$ ( $\mathrm{T}=$ type strain) had been isolated from a 'blown', temperature-abused vacuum pack of raw lamb, using methods described previously (Broda et al., 1996). This meat-derived strain was revived from freeze-dried culture in peptone yeast extract glucose starch (PYGS) broth (Lund et al., 1990) and subcultured onto Columbia Blood Agar (CBA; Oxoid) containing 5\% (v/v) sheep blood. These agar plates were incubated at $26{ }^{\circ} \mathrm{C}$ for $72 \mathrm{~h}$.

Reference strains of Clostridium xylanolyticum (DSM $6555^{\mathrm{T}}$ ), Clostridium aerotolerans (DSM 5434 ${ }^{\mathrm{T}}$ ), Clostridium sphenoides (DSM 632 $)$ and Clostridium celerecrescens (DSM 5628 ${ }^{\mathrm{T}}$ ) were obtained from the Deutsche Sammlung von Mikroorganismen und Zellkulturen (DSMZ), Braunschweig, Germany. Reference strains were revived from freeze-dried material in PYGS broth and plated on to CBA supplemented with $5 \%(\mathrm{v} / \mathrm{v})$ sheep blood. All reference strains were grown at $37^{\circ} \mathrm{C}$ for $48 \mathrm{~h}$.

Phenotypic characterization. Colony morphology was described for strain SPL $73^{\mathrm{T}}$ grown on the surface of CBA with $5 \%(\mathrm{v} / \mathrm{v})$ sheep blood at $26^{\circ} \mathrm{C}$ for $72 \mathrm{~h}$. The morphology and ultrastructure of vegetative cells and spores were determined for the strain after growth in PYGS broth at $26^{\circ} \mathrm{C}$ for $48 \mathrm{~h}$ and 3 months, respectively. Vegetative cell and spore morphology was determined using a phasecontrast light microscope (Leitz Orthoplan). Cell- and spore ultrastructure was examined using a transmission electron microscope (Philips EM 400), as described previously (Broda et al., 1999). The presence of flagella was determined using a negatively stained 48-h PYGS broth culture and the transmission electron microscopy.

Vegetative cells of strain SPL73 ${ }^{\mathrm{T}}$ were Gram-stained using the method of Johnson et al. (1995) and the Gram type was also determined using a KOH test (Powers, 1995). The cell wall type was determined using transmission electron microscopy.

Physiological tests were conducted in anaerobic peptone yeast extract (PY) broth (Holdeman et al., 1977) with the glucose concentration adjusted to $0 \cdot 5 \%$ (w/v). Physiological tests were performed, as described previously (Broda et al., 1999), in Hungate tubes containing broth inoculated with $2 \%(\mathrm{v} / \mathrm{v})$ exponentially growing culture. The potential for growth at $20 \mathrm{pH}$ values ranging from 4.5 to $9 \cdot 2$ was determined at $26^{\circ} \mathrm{C}$, the $\mathrm{pH}$ of the medium being kept constant by the addition of sterile, anaerobic potassium phosphate buffer. Growth rates at $\mathrm{pH} 7 \cdot 0$ were obtained for 42 temperatures ranging from -1.5 to $47 \cdot 0^{\circ} \mathrm{C}$.
Substrate utilization for strain SPL $73^{\mathrm{T}}$ was tested anaerobically at $26^{\circ} \mathrm{C}$ and an initial $\mathrm{pH}$ of $7 \cdot 0$. This biochemical test was conducted according to Holdeman et al. (1977) in PY broth containing $0 \cdot 1 \%(\mathrm{w} / \mathrm{v})$ yeast extract for the range of substrates described previously (Broda et al., 1999). Fermentation products were determined for strain SPL73 ${ }^{\mathrm{T}}$ grown in PYGS broth at $26^{\circ} \mathrm{C}$ for $10 \mathrm{~d}$. Ether extracts of volatile fatty acids and alcohols, and methyl esters of nonvolatile fatty acids, were prepared according to Holdeman et al. (1977) and analysed as described previously (Broda et al., 1999).

Strain SPL73 ${ }^{\mathrm{T}}$ was tested for toxicity in mice using procedures described in the Bacteriological Analytical Manual of the Food \& Drugs Administration (Solomon et al., 1995).

Xylanolytic activity. The ability of strain SPL $73^{\mathrm{T}}$ to degrade xylan was initially determined on PY agar containing $3 \%$ (w/v) oat-spelt xylan (Sigma) after $72 \mathrm{~h}$ incubation at $26^{\circ} \mathrm{C}$. To determine xylanase activity secreted into culture supernatant, the strain was grown at $26{ }^{\circ} \mathrm{C}$ for $72 \mathrm{~h}$ in PY broth supplemented with $0.5 \%(\mathrm{w} / \mathrm{v})$ oat-spelt xylan. A cell-free culture supernatant was prepared by centrifugation of the culture at $12000 \mathrm{~g}$ for $15 \mathrm{~min}$ subsequent sonication of the supernatant and then further centrifugation. Xylanase activity was measured at both $\mathrm{pH} 5.6$ and $\mathrm{pH} 7.0$ by determining reducing-sugar (xylose) release. Enzyme activity at each $\mathrm{pH}$ was tested in the reaction mixtures containing culture supernatant, oat-spelt xylan and potassium phosphate buffer. The final concentrations of xylan and potassium phosphate in each mixture were $1 \%(\mathrm{w} / \mathrm{v})$ and $80 \mathrm{mM}$, respectively. These reaction mixtures were incubated at $26^{\circ} \mathrm{C}$ for $1 \mathrm{~h}$. The reducing sugar formed was measured using the dinitrosalicilic acid method (Miller, 1959). One unit of xylanase activity secreted in $1 \mathrm{ml}$ culture supernatant was defined as the activity that released $1 \mu \mathrm{mol}$ xylose in $1 \mathrm{~min}$.

16S rRNA sequence determination and phylogenetic analysis. For 16S rRNA sequence determination, strain SPL $73^{\mathrm{T}}$ was grown in PYGS broth at $25^{\circ} \mathrm{C}$ for $48 \mathrm{~h}$. DNA was isolated using the method of Marmur (1961), modified as described by Johnson (1994). The G+C content (mol \%) of the DNA from the strain was determined according to the method of Mesbah et al. (1989).

The 16S rRNA sequence was determined from the PCRamplified 16S rDNA fragment (Broda et al., 1999). The PCR fragment was purified with the Wizard purification kit (Promega, Dade Diagnostics), according to the manufacturers' instructions, and sequenced directly in an ABI 377 automated sequencer (Perkin-Elmer, Applied Biosystems). Forward-and reverse sequences of the 16S rDNA gene were obtained using sequencing conditions and primers described previously (Broda et al., 1999). The sequences were aligned using Sequence Navigator (Perkin-Elmer) and corrected manually in agreement with the electropherograms and the reading of complementing and overlapping fragments. Preliminary sequence analysis was performed on Silicon Graphics Indigo 2 using the GCG package (Devereux et al., 1984). Sequences were aligned using the program PILEUP (Feng \& Doolittle, 1987) with low gap weighting and low gap extension weighting. There was little length polymorphism between the sequences selected for the phylogenetic analysis and so the alignment was unequivocal and no manual adjustments were required. A total of 1395 characters of the aligned sequences were used for the phylogenetic reconstruction, with gaps being treated as missing data. Phylogenetic analysis was performed with 

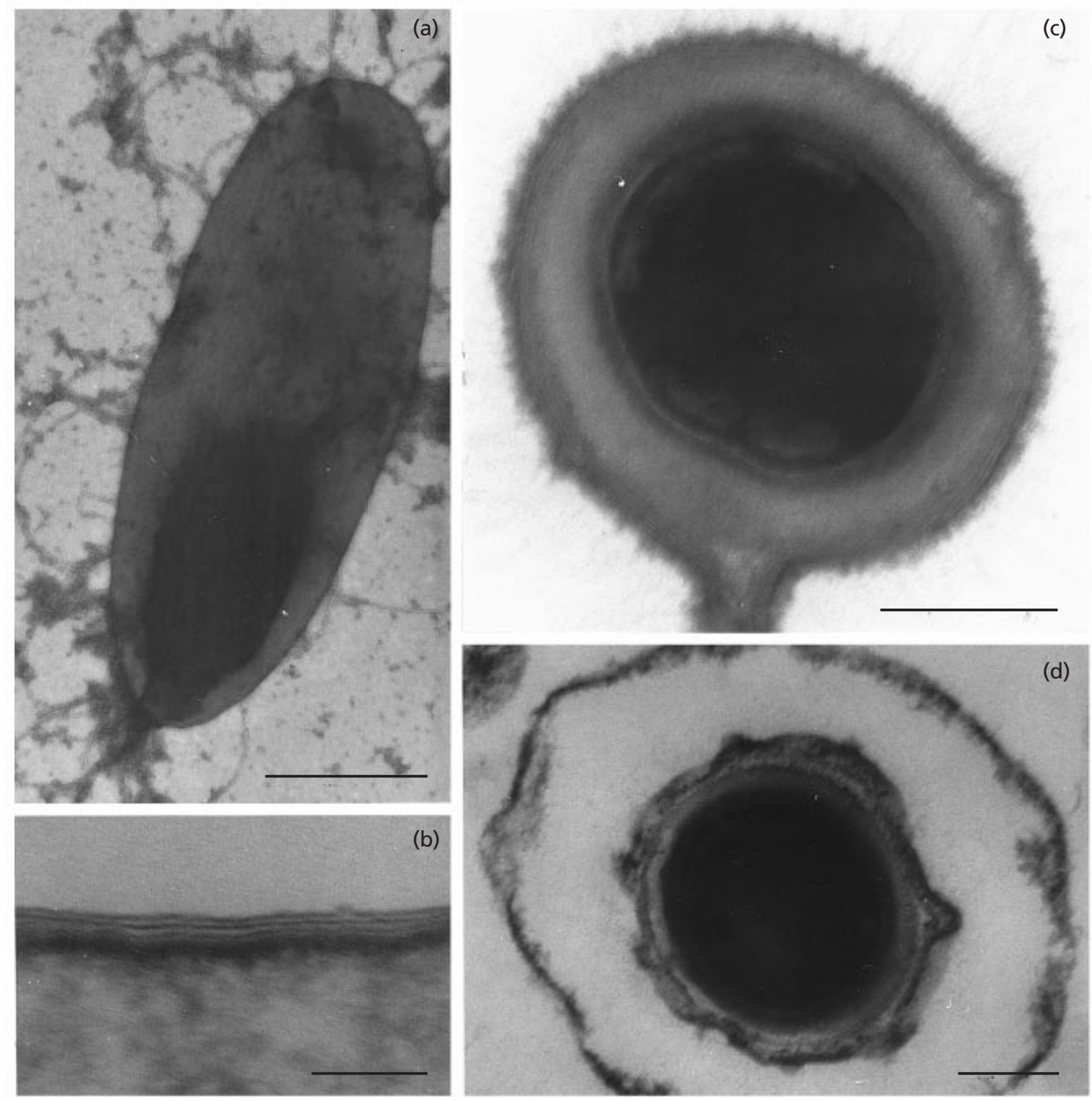

Fig. 1. Electron micrographs of cells of strain $S P L 73^{\top}$ showing peritrichous flagella in a sporulated cell (a), the multilayer cell wall (b), a thin section of a sporulated cell (c) and a thin section of a mature spore (d). Bars, $0.5 \mu \mathrm{m}(\mathrm{a}), 0.1 \mu \mathrm{m}(\mathrm{b})$ and $0.3 \mu \mathrm{m}(\mathrm{c}, \mathrm{d})$.

both maximum-parsimony (MP) and maximum-likelihood (ML) using the program PAUP* (Swofford, 1996). MP-based analyses were performed using a branch and bound search. For MP bootstrap analysis, 2000 heuristic replicate analyses were carried out, each with 10 random sequence additions. ML-based analyses were performed using the HKY85 (Hasegawa et al., 1985) substitution model. Rates were assumed to follow a gamma distribution and the gamma shape parameter and transition to transversion ratios were estimated from the most parsimonious tree. ML bootstrap analysis was performed using the same model with 100 heuristic replicates.

Relatedness to phylogenetically related clostridia. The relatedness of strain SPL73 ${ }^{\mathrm{T}}$ to phylogenetically related clostridia was assessed using SDS-PAGE of total soluble cell proteins and also by means of cellular fatty acid analysis.

Samples and a high-range protein standard (Bio-Rad) for SDS-PAGE were prepared as described previously (Broda et al., 1999). SDS-PAGE was performed using the discon- tinuous buffer system of Laemmli (1970) in either 8-16\% gradient $\mathrm{Tris} / \mathrm{HCl}$ or $10 \%$ Tris $/ \mathrm{HCl}$ polyacrylamide minigels (Bio-Rad) in a Ready Gel Cell vertical gel apparatus (Bio-Rad). Electrophoresis was carried out at constant voltage of $150 \mathrm{~V}$ for $1 \mathrm{~h}$ and the gel was stained with Coomassie blue R-250 (BDH).

For cellular fatty acid analysis, fatty acid methyl esters (FAMEs) were extracted as described by Kuykendall et al. (1988). The C10 to C20 fatty acid identification and quantification was performed using a Hewlett Packard 6890 gas chromatograph, as described previously (Broda et al., 1999).

\section{RESULTS}

\section{Phenotypic characterization}

The colonies of strain SPL $73^{\mathrm{T}}$ grown on the surface of CBA containing $5 \%$ sheep blood were circular, $0 \cdot 8$ $2.5 \mathrm{~mm}$ in diameter, possessed entire margins and were 

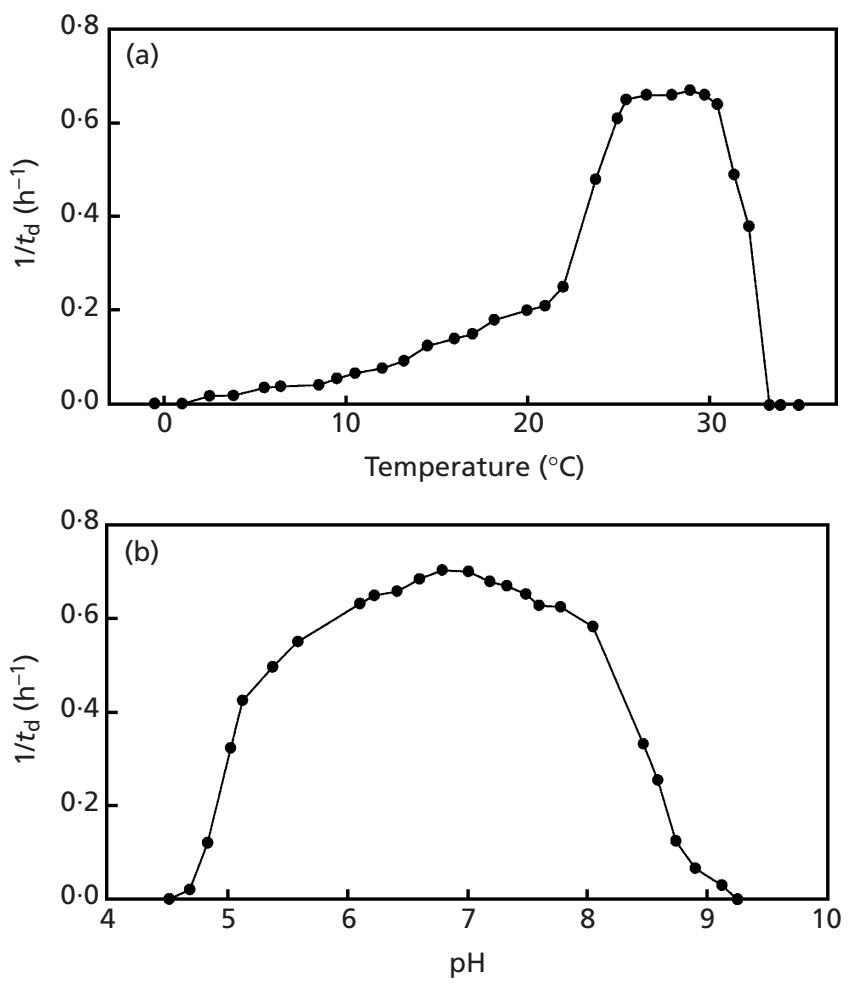

Fig. 2. Growth of strain $S P L 73^{\top}$ at various incubation temperatures at $\mathrm{pH} 7.0$ (a) and at various $\mathrm{pH}$ values at $26^{\circ} \mathrm{C}(\mathrm{b})$. $t_{\mathrm{d}}$, Doubling time.

greyish white, translucent, raised, convex, shiny and $\beta$ haemolytic. Cells in the exponential growth phase occurred singly as tapered straight to slightly bent rods $1.8-2.8 \mu \mathrm{m}$ long and $0.5-0.8 \mu \mathrm{m}$ wide. Both nonsporulated and sporulated cells were motile by means of peritrichous flagella (Fig. 1a). Electron micrographs of ultrathin sections of vegetative cells confirmed that the organism was rod-shaped. The multilayer cell wall was observed in ultrathin sections of vegetative cells of the strain (Fig. 1b). Conventional Gram-staining and the $\mathrm{KOH}$ reaction were indicative of a Gram-negative cell wall type. During the late stationary growth phase, elliptical, subterminal spores were formed (Fig. 1c). The mature spores had a fully developed endospore structure (Fig. 1d). Spores did not swell the maternal cells.

No growth of strain SPL $73^{\mathrm{T}}$ occurred on aerobic CBA containing $5 \%$ sheep blood. Strain $\mathrm{SPL}^{2} 3^{\mathrm{T}}$ grew optimally anaerobically between 25.5 and $30.0{ }^{\circ} \mathrm{C}$ (Fig. 2a). The lowest and highest temperatures at which growth of this strain was observed were 2.5 and $32.2{ }^{\circ} \mathrm{C}$, respectively. The optimal $\mathrm{pH}$ for anaerobic growth was $6 \cdot 8-7 \cdot 0$ and growth occurred at $\mathrm{pH}$ values between 4.7 and $9 \cdot 1$ (Fig. 2b).

Strain SPL73 ${ }^{\mathrm{T}}$ was saccharoclastic, but not proteolytic. Little, if any, growth of the meat strain occurred in media containing peptone and yeast extract but lacking added carbohydrate. Similarly, only little growth of strain SPL73 ${ }^{\mathrm{T}}$ occurred in basal medium (Holdeman et al., 1977) containing carbohydrate but lacking peptone, tryptone and yeast extract. In PY broth without yeast extract, the meat strain reached about half the level of turbidity produced in broth supplemented with yeast extract. The substrates fermented by strain SPL $73^{\mathrm{T}}$ in PY broth were arabinose, cellobiose, fructose, galactose, glucose, inulin, lactose, maltose, mannose, rhamnose, raffinose, salicin, sucrose and xylose. The substrates not fermented were adonitol, dextran, inositol, mannitol, sorbitol, sorbose and trehalose. Starch was hydrolysed and hydrogen sulphide was produced. Gelatin and aesculin were not hydrolysed, lecithinase and lipase activities were absent, meat and casein were not digested and the milk reaction was negative. Neither indole nor ammonia was produced, nitrate was not reduced, oxidase activity and catalase activity were absent and urea was not hydrolysed. No growth was observed in the presence of bile. The addition of Tween 80 did not stimulate growth. The major fermentation products formed by strain SPL73 ${ }^{\mathrm{T}}$ in PYGS broth were acetate, formate, lactate, ethanol, butyrate, butanol, hydrogen and carbon dioxide.

The supernatant of the broth culture of strain SPL73 was not toxic to mice.

\section{Xylanolytic activity}

On medium containing $3 \%$ oat-spelt xylan, colonies of strain SPL $73^{\mathrm{T}}$ were surrounded by clear zones indicative of xylan degradation. At $26^{\circ} \mathrm{C}$, the xylanase activity secreted into the culture supernatant of this strain was $0 \cdot 110 \mathrm{U} \mathrm{ml}^{-1}$ at $\mathrm{pH} 7 \cdot 0$ and $0.073 \mathrm{U} \mathrm{ml}^{-1}$ at pH 5.6.

\section{$16 \mathrm{~S}$ rRNA sequence determination and phylogenetic analysis}

The $\mathrm{G}+\mathrm{C}$ content of the DNA of strain SPL73 ${ }^{\mathrm{T}}$ was $38.4 \mathrm{~mol} \%$.

The 16S rRNA sequence of strain SPL $73^{\mathrm{T}}$ containing a continuous stretch of 1502 nucleotides (approximately positions 8-1518 according to Escherichia coli numbering) was used to search the GenBank and Ribosomal Database Project libraries. Sequence searches showed that strain SPL73 ${ }^{\mathrm{T}}$ was phylogenetically most closely associated with the Clostridium subphylum (data not shown). The results of the sequence similarity calculations indicated that the nearest relatives of strain SPL73 ${ }^{\mathrm{T}}$ are $C$. aerotolerans $(97 \cdot 7 \%), C$. xylanolyticum $(97.6 \%), C$. celerecrescens $(97 \cdot 0 \%)$ ) and $C$. sphenoides $(96 \cdot 3 \%)$.

Of the aligned 1395 characters there were 152 parsimony-informative sites. The search using MP as an optimality criterion generated a single most parsimonious tree of length 487 . The consistency index of 


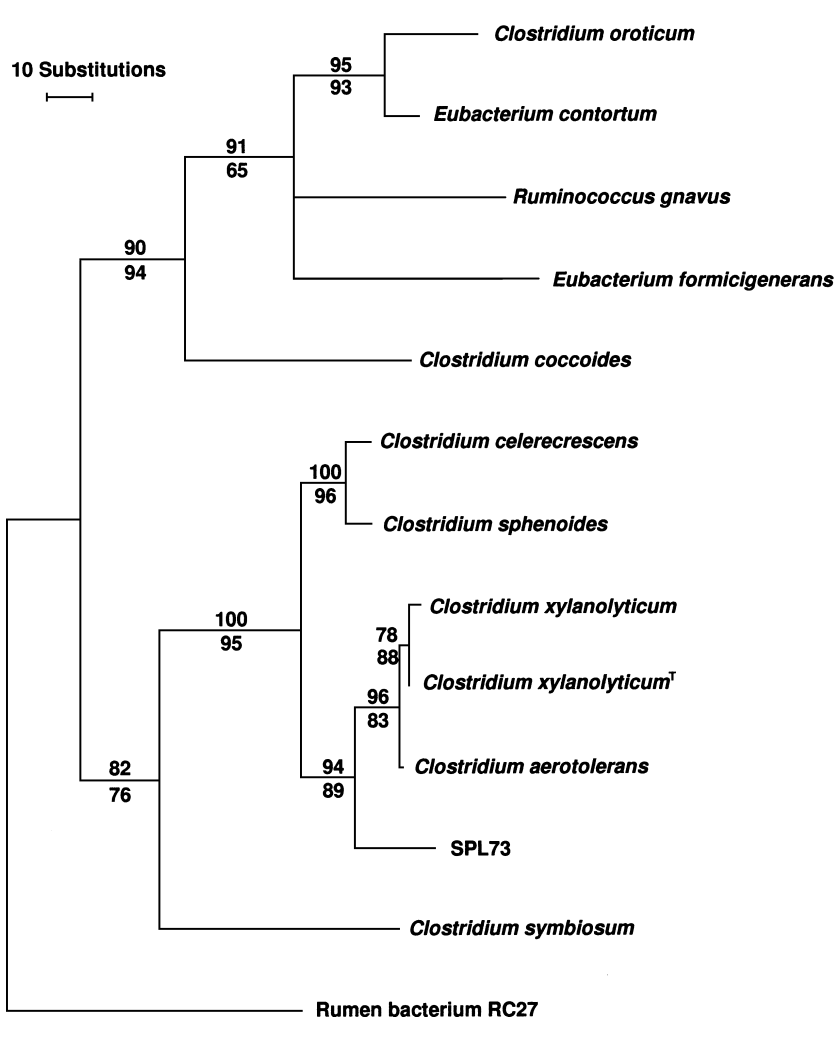

Fig. 3. Consensus maximum-parsimony and maximumlikelihood tree generated from aligned 16S rRNA gene sequences. The values above branches indicate the level of support derived from maximum-parsimony bootstrap analyses of 2000 replicates. The values below branches indicate the level of support derived from maximum-likelihood bootstrap analyses of 100 replicates. The following reference strains were used in phylogenetic analyses: Clostridium aerotolerans DSM $5434^{\top}$ (X76163), Clostridium celerecrescens DSM 5628 ${ }^{\top}$ (X71848), Clostridium coccoides DSM 2088 (M59090), Clostridium oroticum ATCC $13619^{\top}$ (M59109), Clostridium sphenoides DSM $632^{\top}$ (X73449), Clostridium symbiosum ATCC 14940 ${ }^{\top}$ (M59112), Clostridium xylanolyticum DSM 6555 ${ }^{\top}$ (X71855), Clostridium xylanolyticum ATCC 4963 (X76739), Eubacterium contortum ATCC $25540^{\top}$ (L34615), Eubacterium formicigenerans ATCC $27755^{\top}$ (L34619) and Ruminococcus gnavus ATCC 29149 ${ }^{\top}$ (L76597). Unidentified rumen bacterium RC27 (AF001716) was used as an outgroup. Bar, 10 nucleotide substitutions.

this tree was 0.690 and the retention index was 0.659 . The ML tree differed from the MP tree in the branching order of Ruminococcus gnavus and Eubacterium formicigenerans. This difference, however, did not affect the phylogenetic position of strain SPL73 ${ }^{\mathrm{T}}$. The consensus MP and ML tree is shown in Fig. 3.

Detailed phylogenetic analyses placed strain SPL $73^{\mathrm{T}}$ within cluster XIVa of the genus Clostridium (sensu Collins et al. 1994). In this cluster, strain SPL73 ${ }^{\mathrm{T}}$ was located within a unit composed of $C$. xylanolyticum and $C$. aerotolerans. Within this unit, however, strain SPL $73^{\mathrm{T}}$ represented a distinct branching line. The robustness of this grouping was well supported by the results of both MP and ML bootstrap analyses ( 94 and $89 \%$, respectively).

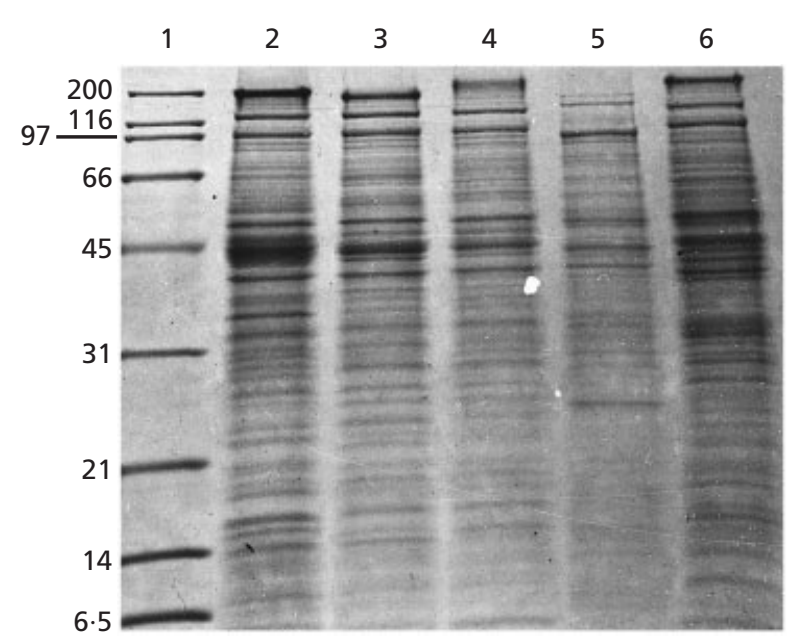

Fig. 4. SDS-PAGE of soluble cell proteins from strain $\mathrm{SPL73}^{\top}$ and phylogenetically related clostridia. Electrophoresis was carried out in $8-16 \%$ gradient Tris/ $\mathrm{HCl}$ polyacrylamide gel. Lanes: 1, broad-range protein standard; 2, strain $\mathrm{SPL73}^{\mathrm{T}} ; 3, \mathrm{C}$. xylanolyticum (DSM 6555'); 4, C. aerotolerans (DSM 5434 ${ }^{\top}$ ); 5 , C. celerecrescens (DSM 5628 $)$; 6, C. sphenoides (DSM 632 ${ }^{\top}$ ). The values on the left of lane 1 indicate the positions of protein standards $(\mathrm{kDa})$.

\section{Relatedness to phylogenetically related clostridia}

Gel electrophoresis of soluble cell proteins demonstrated that there were distinct differences between the profiles of meat strain SPL73 ${ }^{\mathrm{T}}$ and those of its phylogenetic relatives C. xylanolyticum (DSM $6555^{\mathrm{T}}$ ), C. aerotolerans (DSM 5434 ${ }^{\mathrm{T}}$ ), C. sphenoides (DSM $632^{\mathrm{T}}$ ) and C. celerecrescens (DSM $5628^{\mathrm{T}}$ ). The main dissimilarities between these profiles are differences in the concentrations and positions of major protein bands at approximately $45 \mathrm{kDa}$ and of minor bands (Fig. 4).

The major fatty acids detected in the cell extract of strain SPL73 ${ }^{\mathrm{T}}$ were myristic $(\mathrm{C} 14: 0,3.9 \%)$, palmitic (C16:0, 17.8\%), palmitoleic (C16:1, 6.6\%) and oleic $(\mathrm{C} 18: 1,5.0 \%)$ acids. Distinct differences were observed between the cellular fatty acid pattern of the meat strain and the patterns of its phylogenetic neighbours (Table 1). The cellular fatty acid pattern of C. xylanolyticum (DSM $6555^{\mathrm{T}}$ ) differed from the pattern of strain SPL $73^{\mathrm{T}}$ by the presence of stearic acid (C18:0) and three unknown compounds (equivalent chain lengths $15 \cdot 672,17 \cdot 633$ and $18 \cdot 475$ ). In addition, the cellular fatty acid composition of $C$. xylanolyticum $\left(\right.$ DSM $\left.6555^{\mathrm{T}}\right)$ differed from that of the meat strain in the proportion of palmitic $(\mathrm{C} 16: 0)$ and palmitoleic (C16:1) acids formed. The cellular fatty acid pattern of C. aerotolerans (DSM 5434 ${ }^{\mathrm{T}}$ ) contained only two fatty acids, contrasting with the eight associated with the meat strain. The pattern of $C$. sphenoides (DSM 632 $)$ contained a higher proportion of palmitic acid (C16:0) and a lower proportion of palmitoleic acid (C16:1) relative to strain SPL73 ${ }^{\mathrm{T}}$. The pattern of C. sphenoides 
Table 1. Differences in cellular fatty acid composition of strain $\mathrm{SPL} 73^{\top}$ and phylogenetically related clostridia (values are percentage of total peak area)

1, SPL73 ${ }^{\mathrm{T}} ; 2$, Clostridium xylanolyticum DSM $6555^{\mathrm{T}} ; 3$, Clostridium aerotolerans DSM 5434 $;$; , Clostridium sphenoides DSM 632 ${ }^{\mathrm{T}}$; 5 , Clostridium celerecrescens DSM $5628^{\mathrm{T}}$.

\begin{tabular}{|lcccccc|}
\hline $\begin{array}{l}\text { Equivalent chain } \\
\text { length }\end{array}$ & FAME* & $\mathbf{1}$ & $\mathbf{2}$ & $\mathbf{3}$ & $\mathbf{4}$ & $\mathbf{5} \dagger$ \\
\hline $14 \cdot 000$ & & & & & & \\
$15 \cdot 350$ & $14: 0$ & $3 \cdot 9$ & $4 \cdot 3$ & - & $2 \cdot 4$ & $9 \cdot 2$ \\
$15 \cdot 672$ & Unknown & $3 \cdot 5$ & - & - & $1 \cdot 9$ & - \\
$16 \cdot 000$ & Unknown & - & $3 \cdot 5$ & - & $1 \cdot 8$ & $1 \cdot 2$ \\
$16 \cdot 398$ & $16: 0$ & $17 \cdot 8$ & $3 \cdot 0$ & $19 \cdot 6$ & $30 \cdot 3$ & $14 \cdot 0$ \\
$17 \cdot 538$ & $16: 1$ & $6 \cdot 6$ & $1 \cdot 7$ & - & $3 \cdot 9$ & $1 \cdot 0$ \\
$17 \cdot 633$ & Unknown & $9 \cdot 2$ & $12 \cdot 6$ & $8 \cdot 3$ & $6 \cdot 8$ & $3 \cdot 2$ \\
$18 \cdot 000$ & Unknown & - & $5 \cdot 5$ & - & $6 \cdot 1$ & - \\
$18 \cdot 362$ & $18: 0$ & - & $4 \cdot 1$ & - & $4 \cdot 5$ & $5 \cdot 5$ \\
$18 \cdot 404$ & $18: 1$ & $5 \cdot 0$ & $3 \cdot 1$ & - & $6 \cdot 0$ & $5 \cdot 6$ \\
$18 \cdot 493$ & Unknown & $6 \cdot 3$ & $5 \cdot 4$ & - & $2 \cdot 7$ & - \\
$18 \cdot 475$ & Unknown & $3 \cdot 0$ & - & - & $6 \cdot 8$ & - \\
& Unknown & - & $2 \cdot 6$ & - & $2 \cdot 9$ & $1 \cdot 9$ \\
\hline
\end{tabular}

* Only C10 to C20 fatty acids are listed. Concentrations of individual fatty acids are expressed as the percentage of total peak area that might have included peaks of straight chain and/or branched fatty acids with an effective chain length of less than 10, as well as some unknown compounds.

$\dagger$ For $C$. celerecrescens, only fatty acids occurring in concentrations over $1 \%$ are listed. With this strain, a number of fatty acids were also detected at concentrations below $1 \%$. Because these fatty acids did not occur in the remaining strains, they have been omitted from this table because of low comparative values.

also contained stearic acid (C18:0) and three unknown compounds (equivalent chain lengths 15.672, 17.633 and 18.475), which were absent from the pattern for the meat strain.

\section{DISCUSSION}

The results of $16 \mathrm{~S}$ rRNA sequence similarity analysis and database searches show that strain SPL $73^{\mathrm{T}}$ was most similar to $C$. aerotolerans (DSM 5434 ${ }^{\mathrm{T}}$ ), $C$. xylanolyticum (DSM 6555 $5^{\mathrm{T}}$ ), C. celerecrescens (DSM $5628^{\mathrm{T}}$ ) and $C$. sphenoides (DSM $632^{\mathrm{T}}$ ). The results of phylogenetic analyses demonstrate, however, that the meat strain represents a distinct branch within a phylogenetic unit containing two strains of $C$. xylanolyticum and C. aerotolerans (Fig. 3). The meat strain characterized in this study was readily distinguished from its phylogenetic neighbours by its soluble protein profiles and cellular fatty acid profiles. In addition, strain SPL $73^{\mathrm{T}}$ differed from its phylogenetic neighbours in terms of phenotypic characteristics (Table 2). The phylogenetic relatives of strain SPL73 ${ }^{\mathrm{T}}$ are mesophiles and grow optimally at temperatures between 30 and $38^{\circ} \mathrm{C}$ (Cato et al., 1986; van Gylswyk \& van der Toorn, 1987; Palop et al., 1989; Rogers \& Baecker, 1991), whereas the meat strain is unable to grow at temperatures above $32.2{ }^{\circ} \mathrm{C}$ and grows optimally between 25.5 and $30.0^{\circ} \mathrm{C}$. In contrast to $C$. aerotolerans, strain SPL73 ${ }^{\mathrm{T}}$ was obligately anaerobic. Additional phenotypic properties that differentiate strain SPL $73^{\mathrm{T}}$ from $C$. xylanolyticum and $C$. aerotolerans were the fermentation of arabinose and lactose (unlike C. xylanolyticum the meat strain ferments these two carbohydrates) and the fermentation of inulin and trehalose (in contrast to $C$. aerotolerans, the meat strain ferments inulin but not trehalose) (van Gylswyk \& van der Toorn, 1987; Rogers \& Baecker, 1991). Unlike strain SPL73 ${ }^{\mathrm{T}}$, its two other nearest phylogenetic neighbours, $C$. sphenoides and C. celerecrescens, produce indole and ferment a different range of carbohydrates (Cato et al., 1986; Palop et al., 1989).

The results of detailed phylogenetic analyses conducted in this study placed strain SPL $73^{\mathrm{T}}$ in cluster XIVa of the genus Clostridium (sensu Collins et al. 1994). Members of cluster XIVa are phylogenetically distinct from sensu stricto clostridia belonging to cluster I (Collins et al., 1994), i.e. rRNA homology group I (Johnson \& Francis, 1975). Cluster XIVa contains phenotypically and phylogenetically heterogeneous micro-organisms that include non-sporeforming cocci (e.g. ruminococci), aerotolerant rods (e.g. C. aerotolerans) and other organisms that frequently have one or more characteristic(s) that conflicts with those defined for members of the genus Clostridium (Cato et al., 1986). Future taxonomic reclassification of this cluster, therefore, is likely to define a number of new genera and may result in nomenclatural changes for clostridial species currently contained within the cluster. However, until a taxonomic review of the genus Clostridium is undertaken, strain SPL73 ${ }^{\mathrm{T}}$ can be assigned to the genus Clostridium.

The majority of known psychrotolerant Clostridium spp. appear to form a very diverse group of dominantly Gram-positive, low- $\mathrm{G}+\mathrm{C}$ organisms belonging to cluster I clostridia (Collins et al., 1994). Strain SPL73 ${ }^{\mathrm{T}}$, with its multilayer thin-section profile of cell wall, its $\mathrm{G}+\mathrm{C}$ content of $38.4 \mathrm{~mol} \%$ and its phylogenetic placement in cluster XIVa, can be readily differentiated from non-proteolytic Clostridium botulinum types B, E and F (Cato et al., 1986), Clostridium estertheticum (Collins et al., 1992), Clostridium algidicarnis (Lawson et al., 1994), Clostridium vincentii (Mountfort et al., 1997), Clostridium frigidicarnis (Broda et al., 1999) and Clostridium gasigenes (Broda et al., 2000). This meat strain differs from Clostridium arcticum (which stains Gram-negative and is not yet characterized with respect to $\mathrm{G}+\mathrm{C}$ content and phylogenetic placement) and from Clostridium fimetarium (which has a $\mathrm{G}+\mathrm{C}$ content of $35.6 \mathrm{~mol} \%$ and also lacks phylogeny data) by its ability to hydrolyse starch and ferment lactose, maltose, raffinose, rhamnose and sucrose (Jordan \& McNicol, 1979; Kotsyurbenko et al., 1995). In ad- 
Table 2. Some properties by which strain SPL73' ${ }^{\top}$ can be differentiated from phylogenetically related clostridia

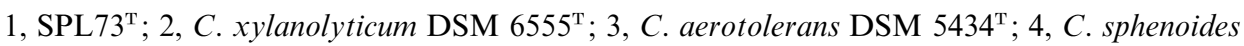
DSM 632 ${ }^{\mathrm{T}} ; 5$, C. celerecrescens DSM 5628 ${ }^{\mathrm{T}}$. Results in parentheses are for some strains of the species. +, Positive; - , negative; w, weak reaction (at pH 5.5-5.9); d, 40-60\% of strains positive;, $\pm 61-89 \%$ of strains positive; NR, not reported; A, acetate; B or b, butyrate; c, caproate; F or f, formate; ib, isobutyrate; iv, isovalerate; $\mathrm{L}$ or 1 , lactate; s, succinate; 2 , ethanol; 4, butanol. Upper-case letters indicate major fermentation products and lower-case letters indicate minor fermentation products.

\begin{tabular}{|lccccc|}
\hline Phenotypic property & $\mathbf{1}$ & $\mathbf{2} *$ & $\mathbf{3 \dagger}$ & $\mathbf{4} \dagger$ & $\mathbf{5} \S$ \\
\hline Maximum growth temp. $\left({ }^{\circ} \mathrm{C}\right)$ & $32 \cdot 2$ & $\mathrm{NR}$ & $<45$ & $<45$ & $\mathrm{NR}$ \\
Optimum growth temp. $\left({ }^{\circ} \mathrm{C}\right)$ & $25 \cdot 5-30 \cdot 0$ & 35 & 38 & $30-37$ & 35 \\
Fermentation products & $\mathrm{A}, \mathrm{F}, \mathrm{L}, \mathrm{b}, 2,4$ & $\mathrm{~F}, \mathrm{~L}, \mathrm{~A}, 2$ & $\mathrm{~A}, \mathrm{~F}, \mathrm{~L}, 2$ & $\mathrm{~A}, 2$ & $\mathrm{~A}, \mathrm{~F}, \mathrm{~B}, \mathrm{ib}, \mathrm{iv}$, \\
& & & & $(\mathrm{F}, \mathrm{s}, \mathrm{l})$ & $\mathrm{c}, 1, \mathrm{~s}, 2$ \\
Gelatin hydrolysis & - & - & - & - & + \\
Indole production & - & - & - & + & + \\
Nitrate reduction & - & - & - & \pm & - \\
Fermentation of: & & & & & \\
Arabinose & + & - & + & $-\mathrm{W}$ & + \\
Inulin & + & $\mathrm{NR}$ & - & - & - \\
Lactose & + & - & + & $+\mathrm{W}$ & $+\mathrm{w}$ \\
Trehalose & - & - & $\mathrm{d}$ & $\mathrm{d}$ & + \\
\hline
\end{tabular}

* Results are from Rogers \& Baecker (1991).

$\dagger$ Results are from van Gylswyk \& van der Toorn (1987).

$\ddagger$ Results are from Cato et al. (1986).

$\S$ Results are from Palop et al. (1989).

dition, strain $\mathrm{SPL}^{\mathrm{T}} \mathrm{3}^{\mathrm{T}}$ is unable to produce indole, whereas $C$. arcticum is able to do so, and strain SPL73 ${ }^{\mathrm{T}}$ ferments arabinose, whereas $C$. arcticum does not. Unlike strain SPL 73 ${ }^{\mathrm{T}}$, Clostridium putrefaciens is nonsaccharolytic (Cato et al., 1986) and Clostridium laramiense reduces nitrate, has lipase activity and ferments a different range of carbohydrates (Kalchayanand et al., 1993; Trüper \& de' Clari, 1997).

The common sources of xylan-fermenting clostridia are farm soil, animal feeds and wood chips (Lamed \& Zeikus, 1980; van Gylswyk \& van der Toorn, 1987; Rogers \& Baecker, 1991). Xylanolytic clostridia (e.g. Clostridium polysaccharolyticum, C. aerotolerans) may also be present in the rumen. However, as strain SPL $73^{\mathrm{T}}$ cannot proliferate at temperatures above $33{ }^{\circ} \mathrm{C}$, well below ruminant body temperature, the source of carcass contamination with this meat strain appears to be extrinsic. Such contamination may occur as a result of contact either with spores that survive passage through the digestive system of slaughter animals or with spores of environmental origin that are carried on the coats of slaughter stock. Alternatively, contamination may occur from a secondary source located within the meat plant, such as the ventilation- or drainage systems.

Results of morphological, biochemical and physiological characterization conducted in this study consistently demonstrate distinct differences between strain SPL73 ${ }^{\mathrm{T}}$ and its nearest taxonomic neighbours. Both the chemotaxonomic characterization data and the unique phylogenetic position of strain SPL73 ${ }^{\mathrm{T}}$ confirm the distinctiveness of the meat strain relative to currently described clostridial species, fulfilling the requirements for polyphasic delineation of bacterial taxa. Therefore, strain SPL $73^{\mathrm{T}}$ merits classification as a new species within the genus Clostridium. For this species, we propose the name Clostridium algidixylanolyticum.

\section{Description of Clostridium algidixylanolyticum sp. nov.}

Clostridium algidixylanolyticum (al.gi.di.xy.la.no. ly'ti.cum. L. adj. algidus cold; Gr. derived M.L. n. xylanum xylan; Gr. adj. lyticus dissolving; N.L. gen. n. algidixylanolyticum cold xylan-dissolving).

Colonies on sheep-blood agar are $0.8-2.5 \mathrm{~mm}$ in diameter, circular with an entire margin, greyish white, translucent and $\beta$-haemolytic. Cells are single, tapered, motile rods $(1.8-2.8 \mu \mathrm{m}$ long and $0.5-0.8 \mu \mathrm{m}$ wide). Elliptical spores do not swell maternal cells and are produced in the late stationary growth phase. Obligately anaerobic. At $\mathrm{pH} 7 \cdot 0$, the micro-organism grows optimally between 25.5 and $30.0{ }^{\circ} \mathrm{C}$. At $26^{\circ} \mathrm{C}$, it grows optimally at $\mathrm{pH} 6 \cdot 8-7 \cdot 0$. Temperature range for 
growth is $2 \cdot 5-32 \cdot 2{ }^{\circ} \mathrm{C}$; $\mathrm{pH}$ range for growth is $4 \cdot 7-9 \cdot 1$. Saccharoclastic and ferments arabinose, cellobiose, fructose, galactose, glucose, inulin, lactose, maltose, mannose, raffinose, rhamnose, salicin, sucrose and xylose. Starch is hydrolysed and xylan is degraded. Fermentation products formed in PYGS broth are acetate, formate, lactate, ethanol, butyrate, butanol, hydrogen and carbon dioxide. The supernatant of the broth culture of the micro-organism is non-toxic to mice. $\mathrm{G}+\mathrm{C}$ content of the DNA is $38.4 \mathrm{~mol} \%$. Isolated from vacuum-packed, temperature-abused raw lamb. The type strain is strain SPL $73^{\mathrm{T}}$ (= DSM $\left.12273^{\mathrm{T}}\right)$.

\section{ACKNOWLEDGEMENTS}

The authors wish to thank Mr D. J. C. Wild for help with the transmission electron microscopy, Mr M. P. Agnew for assistance with chromatography and $\mathrm{Mr} \mathrm{M}$. Wilson for conducting mouse-toxigenicity tests. The Waikato DNA Sequencing Facility is acknowledged for sequencing of the strains. The financial support of the New Zealand Foundation for Research, Science and Technology is gratefully acknowledged.

\section{REFERENCES}

Anonymous (1993). National Advisory Committee on Microbiological Criteria for Foods, US Department of Agriculture Generic HACCP for raw beef. Food Microbiol 10, 449-488.

Bell, R. G. (1997). Distribution and sources of microbial contamination on beef carcasses. J Appl Microbiol 82, 292-300.

Broda, D. M., De Lacy, K. M., Bell, R. G., Braggins, T. J. \& Cook, R. L. (1996). Psychrotrophic Clostridium spp. associated with 'blown pack' spoilage of chilled vacuum-packed red meats and dog rolls in gas-impermeable plastic casings. Int $J$ Food Microbiol 29, 335-352.

Broda, D. M., Lawson, P. A., Bell, R. G. \& Musgrave, D. R. (1999). Clostridium frigidicarnis sp. nov., a psychrotolerant bacterium associated with 'blown pack' spoilage of vacuum-packed meats. Int J Syst Bacteriol 49, 1539-1550.

Broda, D. M., Saul, D. J., Lawson, P. A., Bell, R. G. \& Musgrave, D. R. (2000). Clostridium gasigenes sp. nov., a psychrophile causing spoilage of vacuum-packed meat. Int $J$ Syst Evol Microbiol 50, 107-118.

Cato, E. P., George, W. L. \& Finegold, S. M. (1986). Genus Clostridium Prazmowski 1880, 23 ${ }^{\mathrm{AL}}$. In Bergey's Manual of Systematic Bacteriology, vol. 2, pp. 1141-1200. Edited by P. H. A. Sneath, N. S. Mair, M. E. Sharpe \& J. G. Holt. Baltimore: Williams \& Wilkins.

Collins, M. D., Rodriques, U. M., Dainty, R. H., Edwards, R. A. \& Roberts, T. A. (1992). Taxonomic studies on a psychrophilic Clostridium from vacuum-packed beef: description of Clostridium estertheticum sp. nov. FEMS Microbiol Lett 96, 235-240.

Collins, M. D., Lawson, P. A., Willems, A., Cordoba, J. J., Fernandez-Garayzabal, J., Garcia, P., Cai, J., Hippe, H. \& Farrow, J. A. E. (1994). The phylogeny of the genus Clostridium: proposal of five new genera and eleven new species combinations. Int $J$ Syst Bacteriol 44, 812-826.

Devereux, J., Haeberli, P. \& Smithies, O. (1984). A comprehensive set of sequence analysis programs for the VAX. Nucleic Acids Res 12, 387-395.
Ercolani, G. L. (1997). Note: Occurrence and persistence of culturable clostridial spores on the leaves of horticultural plants. J Appl Microbiol 82, 137-140.

Feng, D.-F. \& Doolittle, R. F. (1987). Progressive sequence alignment as a prerequisite to correct phylogenetic trees. $J \mathrm{Mol}$ Evol 25, 351-360.

Gill, C. O. (1979). A review: intrinsic bacteria in meat. $J \mathrm{Appl}$ Bacteriol 47, 473-486.

van Gylswyk, N. O. \& van der Toorn, J. J. T. K. (1987). Clostridium aerotolerans sp. nov., a xylanolytic bacterium from corn stover and from the rumina of sheep fed corn stover. Int $J$ Syst Bacteriol 37, 102-105.

Hasegawa, M., Kishino, H. \& Yano, T. (1985). Dating of the human-ape splitting by a molecular clock of mitochondrial DNA. J Mol Evol 32, 443-445.

Holdeman, L. V., Cato, E. P. \& Moore, W. E. C. (1977). Anaerobe Laboratory Manual, 4th edn. Blacksburg, VA: Anaerobe Laboratory, Virginia Polytechnic Institute and State University.

Johnson, J. L. (1994). Similarity analysis of DNAs. In Methods for General and Molecular Bacteriology, pp. 655-682. Edited by P. Gerhardt, R. G. E. Murray, W. A. Wood \& N. R. Krieg. Washington, DC: American Society for Microbiology.

Johnson, J. L. \& Francis, B. S. (1975). Taxonomy of the clostridia: ribosomal ribonucleic acid homologies among the species. $J$ Gen Microbiol 88, 229-244.

Johnson, M. J., Thatcher, E. \& Cox, M. E. (1995). Techniques for controlling variability in Gram staining of obligate anaerobes. $J$ Clin Microbiol 33, 755-758.

Jordan, D. C. \& McNicol, P. J. (1979). A new nitrogen-fixing Clostridium species from a high Arctic ecosystem. Can $J$ Microbiol 25, 947-948.

Kalchayanand, N., Ray, B. \& Field, R. A. (1993). Characteristics of psychrophilic Clostridium laramie causing spoilage of vacuumpackaged refrigerated fresh and roasted beef. J Food Prot 56, $13-17$.

Kotsyurbenko, O. R., Nozhevnikova, A. N., Osipov, G. A., Kostrikina, N. A. \& Lysenko, A. M. (1995). A new psychroactive bacterium, Clostridium fimetarium, isolated from cattle manure digested at low temperature. Microbiology (English translation of Mikrobiologiya) 64, 804-810.

Kuykendall, L. D., Roy, M. A., O’Neill, J. J. \& Devine, T. E. (1988). Fatty acids, antibiotic resistance and deoxyribonucleic acid homology groups of Bradyrhizobium japonicum. Int J Syst Bacteriol 38, 358-361.

Laemmli, U. K. (1970). Cleavage of structural proteins during the assembly of the head of bacteriophage T4. Nature 227, 680-685. Lamed, R. \& Zeikus, J. G. (1980). Ethanol production by thermophilic bacteria: relationship between fermentation product yields of and catabolic enzyme activities in Clostridium thermocellum and Thermoanaerobium brockii. J Bacteriol 144, 569-578.

Lawson, P., Dainty, R. H., Kristiansen, N., Berg, J. \& Collins, M. D. (1994). Characterization of a psychrotrophic Clostridium causing spoilage in vacuum-packed cooked pork: description of Clostridium algidicarnis sp. nov. Lett Appl Microbiol 19, 153-157.

Lund, B. M. (1986). Anaerobes in relation to foods of plant origin. In Anaerobic Bacteria in Habitats Other Than Man, pp. 351-372. Edited by E. M. Barnes \& G. C. Mead. Oxford: Blackwell.

Lund, B. M., Graham, A. F., George, S. M. \& Brown, D. (1990). The combined effect of incubation temperature, $\mathrm{pH}$ and sorbic acid 
on the probability of growth of non-proteolytic type B Clostridium botulinum. J Appl Bacteriol 69, 481-492.

Marmur, J. (1961). A procedure for the isolation of deoxyribonucleic acid from microorganisms. J Mol Biol 3, 208-218.

Mesbah, M., Premachandran, U. \& Whitman, W. B. (1989). Precise measurement of the $\mathrm{G}+\mathrm{C}$ content of deoxyribonucleic acid by high-performance liquid chromatography. Int J Syst Bacteriol 39, 159-167.

Miller, G. L. (1959). Use of dinitrosalicilic acid reagent for determination of reducing sugars. Anal Chem 31, 426-428.

Mountfort, D. O., Rainey, F. A., Burghardt, J., Kaspar, H. F. \& Stackebrandt, E. (1997). Clostridium vincentii sp. nov., a new obligately anaerobic, saccharolytic, psychrophilic bacterium isolated from low-salinity pond sediment of the McMurdo Ice Shelf, Antarctica. Arch Microbiol 167, 54-60.

Nottingham, P. M. (1982). Microbiology of carcass meats. In Meat Microbiology, pp. 22-24. Edited by M. H. Brown. London: Applied Science Publishers.

Palop, M. L. L., Valles, S., Piñaga, F. \& Flors, A. (1989). Isolation and characterization of an anaerobic, cellulolytic bacterium,
Clostridium celerecrescens sp. nov. Int J Syst Bacteriol 39, 68-71.

Powers, E. M. (1995). Efficacy of the Ryu nonstaining $\mathrm{KOH}$ technique for rapidly determining Gram reactions of foodborne and waterborne bacteria and yeasts. Appl Environ Microbiol 61, 3756-3758.

Rogers, G. M. \& Baecker, A. A. W. (1991). Clostridium xylanolyticum sp. nov., an anaerobic xylanolytic bacterium from decayed Pinus patula wood chips. Int J Syst Bacteriol 41, 140-143.

Solomon, H. M., Rhodehamel, E. J. \& Kautter, D. A. (1995). Clostridium botulinum. In Food and Drug Administration Bacteriological Analytical Manual, 8th edn, pp. 17.01-17.10. Gaithersburg: AOAC International.

Swofford, D. L. (1996). PAUP*: phylogenetic analysis using parsimony (and other methods), version 4.0. Sunderland, MA: Sinauer.

Trüper, H. G. \& de' Clari, L. (1997). Taxonomic note: necessary correction of specific epithets formed as substantives (nouns) 'in apposition'. Int J Syst Bacteriol 47, 908-909. 